\title{
EL GUARDAJOYAS DE LA INFANTA PAZ DE BORBÓN EN EL MOMENTO DE SU CASAMIENTO
}

\author{
Nuria Lázaro Milla \\ nurialazaromilla@,outlook.com
}

\section{RESUMEN}

Con veinte años, la infanta española Paz de Borbón poseía ya un importante joyero. Así lo demuestra el inventario redactado en 1883 con motivo de sus esponsales, texto que se convierte en una valiosa fuente de información acerca de tipos, motivos decorativos, materiales y tasación de joyas que bien podrían pertenecer a cualquier otra dama de alta sociedad del último tercio del siglo XIX. Entre ellas se han destacado algunas de las que le fueron regaladas, precisamente, por sus nupcias, identificadas gracias a las noticias publicadas por la prensa. Igualmente, la comparación entre el documento y los retratos de la infanta permite el reconocimiento de ciertas de esas joyas.

PALABRAS CLAVE: joyería; inventario; boda real; infanta Paz de Borbón; princesa de Baviera.

\section{PRINCESS PAZ OF BOURBON'S JEWELLERY COLLECTION AT THE MOMENT OF HER WEDDING}

\begin{abstract}
At the age of 20, the Spanish Princess Paz of Bourbon owned an important collection of jewels, as the inventory written in 1883 on the occasion of her marriage demostrates. This text provides valuable information about types, decorative motifs, materials and valuation of jewellery that could belong to any other high society lady of the last third of the nineteenth century. Among them, have been emphasised some jewels that were nuptial presents, identified thanks to news published in press. Also, the comparison between the document and the princess' portraits allows the identification of some of those jewels.
\end{abstract}

KEY WORDS: jewellery; inventory; royal wedding; Princess Paz of Bourbon; Princess of Bavaria. 
El 2 de abril de 1883, en la capilla del Palacio Real de Madrid, la infanta María de la Paz de Borbón y Borbón (Madrid, 23 de junio de 1862 - Múnich, 4 de diciembre de 1946), hija de la reina Isabel II y de Francisco de Asís de Borbón y hermana del rey Alfonso XII ${ }^{1}$, tomaba por esposo a su primo el príncipe Luis Fernando de Baviera, hijo del príncipe Adalberto de Baviera y de la infanta Amalia de Borbón, hermana de su padre.

De acuerdo con el protocolo habitual, el día anterior se habían firmado las capitulaciones matrimoniales ante Vicente Romero y Girón, ministro de Gracia y Justicia y, por ello, notario mayor del Reino. En el documento se enumeran los bienes, de muy diversa índole, que la novia aportó a su vida conyugal ${ }^{2}$, entre ellos sus alhajas, que fueron tasadas en 591.910 pesetas por Celestino de Ansorena, diamantista de la Real Casa ${ }^{3}$.

Pese a su joven edad, eran numerosas las piezas que integraban el joyero de la infanta $\mathrm{Paz}^{4}$. Poseía un aderezo ${ }^{5}$ de brillantes y rubíes (135.000 pesetas) y cinco medios aderezos, formados por pendientes y broche de esmalte, perlas y $\operatorname{rosas}^{6}(1.500$ ptas.); pendientes y broche de amatistas, perlas y medias perlas (200 ptas.); pendientes, broche y colgante de turquesas y diamantes talla brillante y rosa (400 ptas.); pendientes y broche de perlas de color blanco, negro y rosa (300 ptas.) y pendientes y broche con camafeos orlados de brillantes (2.500 ptas.).

Para enriquecer la cabeza disponía de dos diademas, una con trece perlas perillas y mil ochenta y un brillantes ( 85.000 ptas.) y la otra de brillantes con una flor de lis en el centro (20.000 ptas.). Más sencillo era el alfiler con esferas de rosas (4.400 ptas.), destinado a prenderse al peinado o sombrero.

En cuanto a los pendientes, el inventario registra un buen número de ellos. Eran de cuatro perlas y brillantes (12.000 ptas.); de perlas y brillantes, de estilo chinesco (4.000 ptas.); de chatones de brillantes y colgantes (3.750 ptas.); con cuatro brillantes (2.200 ptas.); con dos esmeraldas perillas talla cabujón y dos brillantes (1.300 ptas.); de

\footnotetext{
${ }^{1}$ Para ahondar en su biografía se remite a: María Teresa Álvarez, La infanta Paz de Borbón (Madrid: La Esfera de los Libros, 2011); Paz de Borbón, De mi vida: impresiones (Madrid: Imprenta del Asilo de la Santísima Trinidad, 1909); Paz de Borbón, Cuatro revoluciones e intermedios: setenta años de mi vida (Madrid: Espasa-Calpe, 1935).

2 Archivo General de Palacio (AGP), Administración General, leg. 1.160, exp. 3.

${ }^{3}$ Para conocer la historia de la joyería Ansorena al servicio de la Casa Real, véase: Fernando A. Martín, "Ansorena, joyeros y diamantistas reales", en VV. AA., Ansorena, 150 años en la joyería madrileña (Madrid: Ansorena, 1995), 29-51; Amelia Aranda Huete, "La casa Celestino de Ansorena e Hijos, joyeros de la Corona española", Anales del Instituto de Estudios Madrileños 59 (2019), 57-122.

${ }^{4}$ Algunas de las joyas que le fueron regaladas en sus primeros años de vida pueden consultarse en: Nuria Lázaro Milla, "Joyas compradas con cargo al bolsillo secreto de las infantas Isabel, Pilar, Paz y Eulalia y el príncipe Alfonso de Borbón, 1863-1868”, en coord. Jesús Rivas Carmona e Ignacio José García Zapata, Estudios de Platería. San Eloy 2020 (Murcia: Universidad de Murcia, 2020), 137-149. Las que heredó tras el fallecimiento de su madre se recogen en: Nuria Lázaro Milla, "El reparto de joyas tras la muerte de Isabel II, un proceso problemático", en coord. Alejandro Cañestro Donoso, Scripta artivm in honorem prof. José Manuel Cruz V aldovinos (Alicante: Universidad de Alicante, 2018), 268-295.

${ }^{5}$ Conjunto, más o menos amplio, de joyas realizadas a juego para el adorno de diferentes partes del cuerpo.

${ }^{6}$ Talla caracterizada por tener contorno circular (generalmente), culata plana y corona facetada en triángulos que se reúnen en un vértice central.
} 
esmeraldas y dos brillantes (1.200 ptas.); con ocho perlas y brillantes (1.000 ptas.); con dos perlas, dos brillantes y rosas (1.000 ptas.); con cuatro esmeraldas (400 ptas.); con un par de perlas negras y brillantes (300 ptas.); con esmalte, seis perlas y orla de medias perlas (300 ptas.); de perlas, rubíes y rosas componiendo un círculo (200 ptas.); con dos brillantes y rosas (1.200 ptas.); de turquesas con cerco de brillantes (1.200 ptas.); de turquesas, perlas y rosas (250 ptas.); con cuatro rubíes y orla de brillantes (1.800 ptas.); de brillantes y rubíes (1.300 ptas.); en forma de mariposas de perlas y rosas (150 ptas.); con dos perlas perillas, brillantes y rubíes (1.000 ptas.); de diamantes talla brillante y rosa (900 ptas.); con cuatro perlas y esmalte color turquesa (200 ptas.); con cuatro perlas, dos brillantes y dos rosas (400 ptas.); con cuatro perlas (120 ptas.); con dos brillantes (400 ptas.); de flechas formadas por dos perlas y rosas (260 ptas.); de brillantes y rubíes (650 ptas.); de rubíes orlados de brillantes (1.300 ptas.); con dos perlas, dos esmeraldas y perlitas (600 ptas.); con camafeos rodeados de brillantes (1.700 ptas.); de lapislázuli (100 ptas.); con forma de pájaros realizados con dos perlas y rosas (400 ptas.) y de perlas y rosas (650 ptas.). Además, tenía unos aretes con dos brillantes (300 ptas.) y dos pares de tornillos con una perla en cada pieza (800 y 900 ptas.).

Para el adorno del escote doña Paz recurría a los collares. Disponía de uno de diamantes talla brillante y rosa con perlas y colgantes (36.500 ptas.); de seis hilos de perlas y cierre con camafeo y brillantes (30.400 ptas.); de tipo rivière ${ }^{7}$ con treinta y ocho chatones de brillantes (6.000 ptas.); de esmeraldas, brillantes y rosas (4.000 ptas.); de tres hilos con ciento cuarenta y cuatro perlas y cierre con una perla y brillantes $(74.000$ ptas.); de un hilo con ochenta y dos perlas pequeñas y colgante con cuatro más (600 ptas.); con seis broches de amatistas con rosas incrustadas y orla de perlas (700 ptas.); de plata oxidada con esmalte representando un niño y perlas negras (200 ptas.); con una perla, un brillante y rubíes (140 ptas.) y un hilo de brillantes que estaba siendo elaborado en el momento de redacción del inventario (3.000 ptas.). También contaba con un cierre de collar con esmeralda y brillantes (4.000 ptas.).

Igualmente, la infanta lucía al cuello colgantes y medallones. Al respecto de los primeros, el documento recoge uno de cruz con esmeralda, rubíes y brillantes $(3.800$ ptas.); de rosas, perla y turquesas (1.800 ptas.); de herradura con una perla y diamantes talla brillante y rosa (500 ptas.); con dos turquesas y brillantes alrededor (900 ptas.); dos colgantes de rubíes, esmeraldas, perlas y brillantes que entonces estaban en ejecución (2.000 ptas.) y otro mayor que los anteriores (1.500 ptas.). Como medallones figuran uno con una turquesa y una rosa (280 ptas.); con un brillante en el centro (300 ptas.); en forma de corazón con una turquesa y brillantes (600 ptas.); con retrato y una greca de rosas (600 ptas.) y con rosas y rubíes (1.200 ptas.).

Los broches debieron de ser joyas predilectas para doña Paz dada la cantidad en que aparecen referenciados. Consistían en ocho estrellas de brillantes y perlas (10.000 ptas.); dos flores de lis de brillantes (5.800 ptas.); uno de esmeraldas y diamantes talla brillante y rosa (2.200 ptas.); con una esmeralda y brillantes $(2.500$ ptas.); con forma de perro compuesto por una perla y brillantes (5.000 ptas.); con colgantes, con tres perlas, brillantes y rubíes (1.800 ptas.); figurando un mochuelo realizado con rosas y dos perlas (1.500 ptas.); con nueve hojas de brillantes y rosas

\footnotetext{
${ }^{7}$ Collar, pulsera o pendiente formado por la sucesión de piedras engastadas en garra o chatón.
} 
(15.000 ptas.); con retrato y orla de rosas (1.000 ptas.); con dos cabujones de esmeralda y brillantes (3.500 ptas.); con una amatista, ocho perlas y rosas (800 ptas.); con una amatista, tres perlas y dieciséis medias perlas (200 ptas.); con una amatista, cuatro perlas y rosas incrustadas formando un caballo (150 ptas.); con un granate, cuatro perlas, cerco de rosas y las siglas AEI (300 ptas.); con una amatista (80 ptas.); con inscripción en rosas (400 ptas.); figurando una paleta de pintor con una turquesa, un ópalo, rubíes y rosas (300 ptas.); de turquesas y rosas, con iniciales (200 ptas.); de turquesas y rosas (300 ptas.); en forma de abanico de rosas y rubíes (200 ptas.); de rosas, un rubí y una esmeralda (300 ptas.); con tres perlas y diamantes talla brillante y rosa (700 ptas.); de una mosca sobre cristal hecha con rubíes, un zafiro y una esmeralda (300 ptas.); de perlas, rosas y un granate (150 ptas.); con corona e inscripción en rosas (250 ptas.); con flor en el centro y orla de brillantes (1.000 ptas.); de rosas y una perla negra (500 ptas.); de granates con rosas incrustadas (2.000 ptas.); de granates con corona embutida (200 ptas.); de granates y medias perlas (200 ptas.); de granates y perlitas (250 ptas.); en forma de concha con una perla negra, un brillante y un rubí (600 ptas.); de zafiros, brillantes y rosas, con filigrana (950 ptas.); de lapislázuli y filigrana de oro (200 ptas.); de lapislázuli con una greca de esmalte (300 ptas.); de lapislázuli y perlas (300 ptas.); con iniciales de rosas y rubíes (200 ptas.); con los retratos de Sus Majestades (1.000 ptas.) y una flor de brillantes (10.000 ptas.). Asimismo, como imperdibles poseía uno con espadas en rosas (600 ptas.); otro de espadas con rosas, una perla y un zafiro (700 ptas.); de una bandolina con dos perlas, rosas y rubíes (450 ptas.); de rosas (250 ptas.); con lira, espiga y pluma de rosas (400 ptas.); con pinceles de pintor (150 ptas.); de oro con inscripciones (120 ptas.); con dragón y flecha en rosas (600 ptas.) y con una concha y un lagarto en rosas (160 ptas.). Además, tenía un alfiler con un brillante (220 ptas.) y un pasador de zafiros y rosas (80 ptas.).

La infanta custodiaba un buen número de pulseras en su joyero. Contaba con dos con sesenta y seis perlas, veintidós brillantes y rosas (4.000 ptas.); una con colgante de un perro con incrustación de rosas (600 ptas.); con dos perlas y un brillante (600 ptas.); con un brillante y esmalte negro (1.500 ptas.); con dos zafiros, un topacio y rosas (700 ptas.); con un rubí y diamantes talla brillante y rosa (1.200 ptas.); de brillantes y rosas, con una flor de lis (1.300 ptas.); con un rubí y rosas (320 ptas.); de esmalte encarnado y rosas (1.100 ptas.); con ocho brillantes y tres perlas: una de color negro, otra blanca y la última rosa (1.250 ptas.); con dos lapislázulis y medias perlas (250 ptas.); con la inscripción AVE en rosas y la letra M en esmeraldas (420 ptas.); con una perla y diez brillantes (1.000 ptas.); de esmalte negro con un brillante y rosas (550 ptas.); con un brillante, una perla blanca y otra rosa (1.200 ptas.); con tres conchas (450 ptas.); de turquesas (260 ptas.); en forma de serpiente con un brillante (1.800 ptas.); de esmalte rosa, medias perlas y rosas (600 ptas.); de oro, plata y rosas (1.500 ptas.); con tres letras como colgantes (200 ptas.); de turquesas y rosas (1.200 ptas.); con un granate y medias perlas (250 ptas.); con una flecha y un granate (350 ptas.); de esterilla con brillantes (1.700 ptas.); de oro, lisa (70 ptas.); con cinco perlas (200 ptas.); figurando una cinta con su hebilla ${ }^{8}$ (60 ptas.) y con herraduras de turquesas y brillantes $(1.000$ ptas.).

\footnotetext{
${ }^{8}$ Este tipo de brazalete se denominó jarretera por la semejanza con el emblema de la orden inglesa de caballería del mismo nombre.
} 
Doña Paz adornaba las manos con sortijas. Estas eran de cuatro perlas y catorce rosas (150 ptas.); con un rubí, una esmeralda, un brillante y rosas (340 ptas.); con un zafiro (50 ptas.); de esmalte y rosas (40 ptas.); con un brillante (400 ptas.); con forma de lanzadera ${ }^{9}$ de rosas y zafiros (150 ptas.); con un lapislázuli y corona sobrepuesta (30 ptas.); con cuatro brillantes y un ojo de gato (250 ptas.); con tres perlas y rosas (100 ptas.); con dos rubíes, un brillante y una rosa (150 ptas.); de rubíes y rosas (80 ptas.); de rubíes orlados de brillantes (400 ptas.); con una turquesa y rosas (120 ptas.) y con una turquesa y medias perlas (60 ptas.).

Para llevar en la cintura disponía de un reloj con cerco de medias perlas (300 ptas.) y de dos chatelaines $^{10}$, una de lapislázuli (400 ptas.) y la otra con tres perlas negras, diamantes talla brillante y rosa y un reloj esmaltado y con engaste de rosas (2.200 ptas.).

Como buena católica, tenía alhajas para el ejercicio religioso. Utilizaba dos rosarios de amatistas con una medalla (200 y 350 ptas.) y cruces, recogiendo el inventario una con diecisiete medias perlas (300 ptas.); con once perlas y rosas (800 ptas.); con doce brillantes (600 ptas.); con siete brillantes (600 ptas.); pequeña, con doce brillantes (200 ptas.) y de esmalte (200 ptas.). Además, poseía una aguabenditera (400 ptas.) y un devocionario de oro, esmaltes y brillantes (12.500 ptas.).

Por último, el documento registra otros objetos preciosos, como una sombrilla enriquecida con lapislázuli y rosas (1.400 ptas.), un abanico con incrustaciones (1.000 ptas.) y dos cajas de distinto tamaño con una esmeralda y brillantes $(700 \text { y } 900 \text { ptas. })^{11}$.

El inventario de las alhajas que pertenecieron a la infanta Paz de Borbón en sus primeros veinte años de vida manifiesta, en definitiva, la variedad de artículos suntuosos de los que cualquier dama de alta sociedad del momento se podía rodear. Por ello, expuesto todo lo anterior, resulta interesante analizar y sintetizar la información que brinda el documento.

En primer lugar, destaca la riqueza de los materiales, registrándose esmaltes, perlas (blancas, negras y rosas), piedras preciosas (diamante, esmeralda, rubí y zafiro) y otras gemas (turquesa, amatista, lapislázuli, granate, ópalo, topacio y ojo de gato). Algunas de estas últimas habían sido usadas con discreción en siglos anteriores no solo por cuestión de moda, sino por su limitada accesibilidad hasta que el inicio de los procesos de colonización y la apertura de nuevas vías comerciales favorecieron su empleo, propiciando la insólita diversidad de colores, efectos y texturas nuevos horizontes de expresión artística para los creadores. Por el contrario, extraña que, con contadas excepciones, Celestino de Ansorena no hiciera constar los metales con los

\footnotetext{
${ }_{9}^{9}$ Con forma ahusada.

10 Tipo de joya constituida por uno o varios cuerpos de los que penden ramales de cadenas con un enganche en su extremo, permitiendo que puedan colgar objetos de pequeño tamaño como relojes, llaves, pomas de olor, sellos, estuches de costura o manicura, etc. Su mayor desarrollo se produjo en el siglo XVIII.

11 Para tener una visión global de la joyería de la época se remite a: David Bennett y Daniela Mascetti, Understanding jewellery (Londres: Antique Collectors' Club, 2008); Shirley Bury, Jewellery. The international era, 1789-1910. Vol. II: 1862-1910 (Woodbridge: Antique Collectors' Club, 1997); Michael Koch (ed.), The Belle Époque of French jewellery, 1850-1910 (Londres: Thomas Heneage, 1991); Henri Vever, La bijouterie française au XIX $X^{e}$ siècle, 1800-1900. Vol. II: Second Empire, 1850-1870 (París: H. Floury, 1908); Henri Vever, La bijouterie française au XIX siècle, 1800-1900. Vol. III: Troisième République, 1870-1900 (París: H. Floury, 1908); VV. AA., Joyas del siglo XIX (Barcelona: Planeta-De Agostini, 1989).
} 
que estaban construidas las joyas, aunque por época se trataría de oro (con o sin vistas de plata o platino), plata y, cada vez menos esporádicamente, platino.

El inventario evidencia la profunda aceptación que la joyería sentimental y conmemorativa tuvo a lo largo de todo el siglo XIX en las piezas que incluyen un corazón, un niño, retratos, inscripciones, iniciales y la sigla AEI, adaptación del griego $\dot{\alpha} \varepsilon \dot{\imath}$ (siempre) a las letras capitales de amitié, éternité, infinité (amistad, eternidad, infinitud), o en aquellas otras, como colgantes, broches y pulseras, que solían tener un receptáculo para albergar mechones de cabello o efigies de los seres queridos. Dignas de mención son también las alhajas con símbolos de identificación regia como las flores de lis o las coronas, siendo las segundas habituales a partir de la segunda mitad de la centuria, incluso fuera de los círculos aristocráticos.

La joyería decimonónica, fundamentalmente la de uso diario, cultivó los motivos de fantasía, cuyo catálogo se fue ampliando con el paso de los años. El inventario recoge objetos inanimados como un abanico, una paleta de pintor, pinceles, una pluma, una bandolina, una lira, flechas y espadas. Otros asuntos, como las herraduras, el caballo y los perros han de relacionarse con la denominada joyería deportiva, nacida en la década de 1860, muestra del interés por la cultura del ocio. No obstante, la gran inspiradora fue la naturaleza, figurando en el texto animales (pájaros sin determinar, mochuelo, conchas, mariposas, mosca, serpiente y lagarto), plantas (hojas, flores y espiga) y cuerpos celestes (estrellas). Precisamente, astros, insectos y lagartos poblaron escotes y peinados en las últimas décadas de la centuria. Por su parte, la serpiente, a pesar de haber sido dotada de connotación maligna por la doctrina cristiana, ha sido, desde tiempos inmemoriales, símbolo de regeneración y eternidad por su capacidad de mudar la piel. Es uno de los motivos más antiguos y repetidos de la historia de la joyería, gozando durante todo el siglo XIX de una especial aceptación pues se relacionaba con lo misterioso, convirtiéndose en materia predilecta para los joyeros al permitirles imitar su dermis a través de la experimentación con diferentes técnicas y materiales.

Las antiguas civilizaciones del Mediterráneo y sus vestigios de orfebrería fueron sujeto de reinterpretación por los orífices del siglo XIX, de ahí que en el texto se refieran técnicas como la filigrana o el camafeo, ornamentos como las grecas y la salutación AVE. Si el broche con forma de dragón puede considerarse una pieza neomedieval por el motivo plasmado, el de perro realizado con una perla y brillantes remite a los colgantes renacentistas que recrean seres reales o mitológicos a partir de una gruesa perla barroca; de hecho, podría tratarse del ejecutado en 1843 por Narciso Soria, diamantista de Cámara de Isabel II, el cual costó 9.623 reales, realizado en oro, plata, ciento cuarenta y ocho brillantes con peso de casi 12 quilates y una perla ${ }^{12}$ que procedía de una alhaja con igual asunto que la soberana había heredado de Fernando VII ${ }^{13}$. Por último, también los lugares lejanos o exóticos integraron el repertorio de la joyería decimonónica, como demuestran los pendientes de perlas y brillantes de «estilo chinesco».

12 AGP, Administración General, leg. 907. La factura ya fue publicada por Amelia Aranda Huete, "Panorama de la joyería española durante el reinado de Isabel II", Boletin del Museo e Instituto Camón Ažnar 68 (1997), 17.

${ }^{13}$ AGP, Histórica, c. 152. 


\section{JOYAS NUPCIALES}

Al contrario de lo que sucedía en las capitulaciones redactadas en 1868 con motivo de las nupcias de su hermana Isabel ${ }^{14}$, el texto no diferencia entre las joyas que con anterioridad eran propiedad de doña Paz y las que le fueron obsequiadas por su boda. Para esclarecer este punto resulta esencial la información recabada en los artículos de prensa publicados en torno al magno evento.

Como recuerdo de la petición de mano, el príncipe Luis Fernando agasajó a su prometida con la diadema de diamantes tasada en 20.000 pesetas, con una flor de lis en el centro de la que irradian esquemáticas hojas y elementos lanceolados que trazan un arco conopial, la cual había sido realizada en Múnich ${ }^{15}$ (fig. 1). Doña Paz la estrenó en el concierto celebrado en el Palacio Real para conmemorar tal ocasión y en homenaje a los huéspedes bávaros ${ }^{16}$, y con ella sujetó el velo el día de su enlace ${ }^{17}$. La joya fue vendida por los herederos el 14 de mayo de 2013 en la sala Sotheby's de Ginebra por 173.000 francos suizos. El catálogo de la almoneda aporta la valiosa información de que la flor de lis está montada en tembladera ${ }^{18}$, que la diadema es desmontable ${ }^{19}$ y que los diamantes de que se compone son de talla rosa, brillante y cojín antiguas ${ }^{20}$. El príncipe también entregó una sortija de brillantes, que no se identifica en el inventario, y otra alhaja, sin especificar, que se demoró en ser entregada ${ }^{21}$.

\footnotetext{
${ }^{14}$ Nuria Lázaro Milla, "El inventario de joyas de la infanta Isabel de Borbón y Borbón realizado con motivo de sus nupcias", Librosdelacorte.es 20 (2020), 100-128.

${ }^{15}$ Como curiosidad, por la apuntada elevación del diseño en su centro, la diadema fue descrita como «de forma pompeyana y está formada con hojas de brillantes montados en oro», siendo las vistas de plata o platino [La Época 10.974 (27 de enero de 1883), 3].

${ }^{16}$ La Época 10.972 (25 de enero de 1883), 3.

${ }^{17}$ La Época 11.037 (2 de abril de 1883), 3.

18 También denominada tembleque o tremblant, es un tipo de unión a base de muelle que permite la vibración de ciertos elementos que componen la joya al menor movimiento del portador, creándose un llamativo efecto visual al incidir la luz sobre las superficies en movimiento.

${ }^{19}$ Lo que confirmaría la información ofrecida por los medios: «una magnífica diadema de brillantes que se desarma, y se coloca, parte en el cuello, a modo de collar, y parte en la cabeza» [La Época 10.972 (25 de enero de 1883), 3].

${ }^{20}$ Sotheby's, “Diamond tiara, circa 1900”,http://www.sothebys.com/es/auctions/ecatalogue/2013 Lmagnificent-jewels-and-noble-jewels-ge1302/lot.368.html (última consulta: 6 de mayo de 2020).

${ }^{21}$ La Época 11.003 (26 de febrero de 1883), 3 y La Época 11.030 (26 de marzo de 1883), 3.
} 


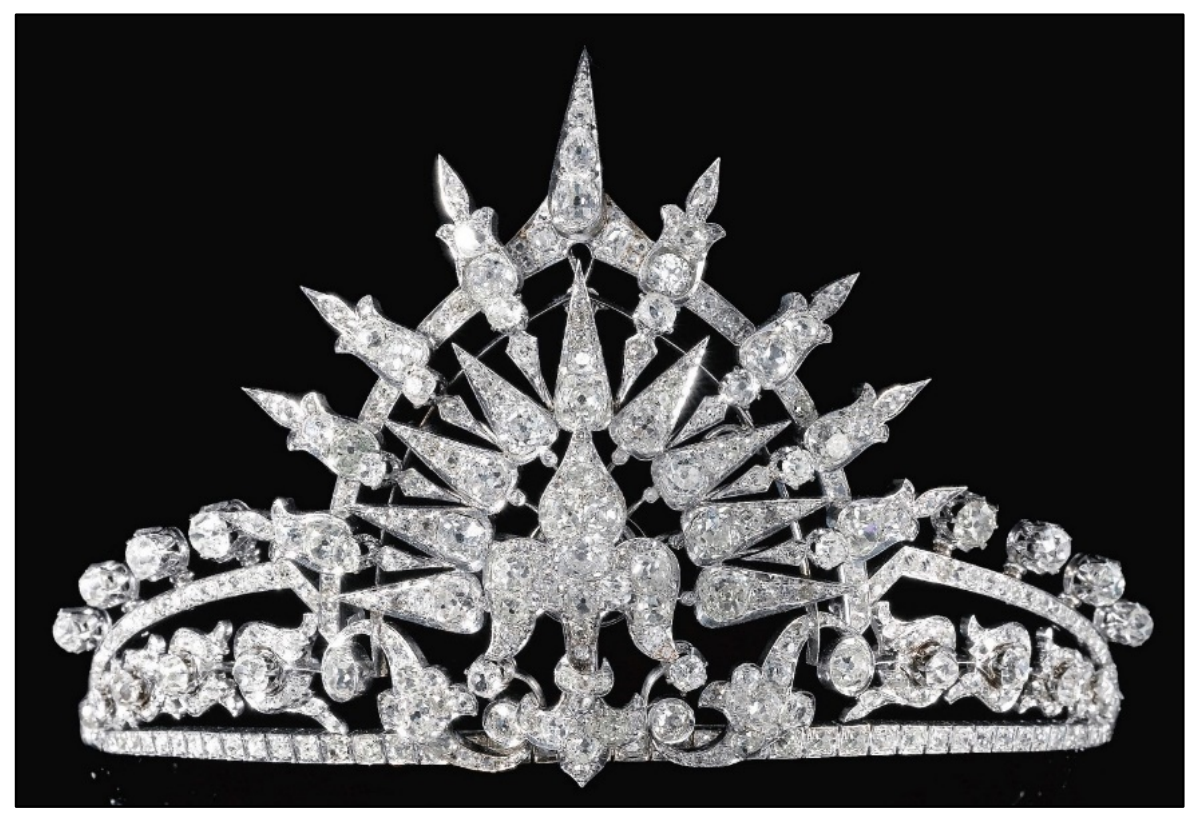

Fig. 1- Anónimo muniqués, Diadema de diamantes con motivo central de flor de lis, h. 1883. Colección privada (fotografía: OSotheby's).

Su hermano, el rey Alfonso XII, se encargó de proporcionarle el ajuar, el vestido de novia, un tiro de cuatro caballos y una alhaja ${ }^{22}$, que quizás fuera el hilo de brillantes (3.000 pesetas) o los dos colgantes de rubíes, esmeraldas, perlas y brillantes (2.000 pesetas) que estaban ejecutándose en el momento en que el documento fue redactado.

Los periódicos coincidieron en señalar que el regalo de la infanta Isabel consistió en un «magnífico» collar de «gruesas y riquísimas perlas», aunque hubo disensión sobre sus detalles, pues unos medios apuntaban que se componía de un hilo que medía vara y media ${ }^{23}$ y otros que lo formaban tres sartas ${ }^{24}$. Fotografías que se comentarán en las páginas siguientes demuestran que el hilo existió, de igual modo que el inventario registra un collar de tres hilos con ciento cuarenta y cuatro perlas y cierre con una perla y brillantes ( 74.000 ptas.). Ha de barajarse la posibilidad de que se tratara de la misma joya, permitiendo su longitud adoptar diferentes posiciones ${ }^{25}$.

La infanta Eulalia demostró el profundo afecto que sentía por su hermana eligiendo para ella dos valiosas piezas que, al parecer, pertenecían a su propio joyero ${ }^{26}$ : por una parte, los pendientes con dos perlas («admirables por su pureza y por su tamaño») en cada uno y guarnecidos de brillantes, apreciados en 12.000 pesetas, y, por

${ }^{22}$ La Época 11.030 (26 de marzo de 1883), 3.

${ }^{23}$ La Correspondencia de España 9.134 (26 de marzo de 1883), 3.

${ }^{24}$ La Época 11.003 (26 de febrero de 1883), 3 y La Época 11.030 (26 de marzo de 1883), 3.

${ }^{25}$ Eso, precisamente, parece indicar la prensa: una de las primeras ocasiones en que doña Paz lució el collar fue en el baile que la Embajada de España en París organizó el 9 de abril para homenajear a los desposados [La Época 11.049 (14 de abril de 1883), 2], que por algún periódico fue descrito como «un collar de perlas de dos hilos de un tamaño raro» [La Iberia 8.206 (13 de abril de 1883), 2].

${ }^{26}$ La Época 11.030 (26 de marzo de 1883), 3. 
otra, la diadema ${ }^{27}$ con engaste de mil ochenta y un brillantes y crestería de trece perlas perillas, tasada en 85.000 pesetas. La diadema adornó los cabellos de doña Paz en el banquete nupcial que el Palacio Real albergó el 3 de abril ${ }^{28}$ y en el baile organizado por la Embajada de España en París el día $9^{29}$.

María Cristina de Habsburgo-Lorena obsequió a su cuñada la flor de brillantes valorada en 10.000 pesetas, que era «admirable» y «de tanto gusto artístico como elegante efecto» ${ }^{30}$, y un abanico de encaje de Alençon con el escudo español tejido y varillaje de marfil con guías "primorosamente trabajadas», que la infanta llevó en las manos el día de su boda ${ }^{31}$. Muchas damas optaron por regalar abanicos al tratarse de imprescindibles complementos de moda; por ejemplo, el ofrecido por la marquesa de Novaliches era de encaje con varillaje de marfil en el que llevaba las cifras coronadas de doña Paz «en brillantes y piedras preciosas de exquisito gusto y elevado valor ${ }^{32}$. Cabe recordar que el inventario recoge un abanico con incrustaciones, tasado en 1.000 pesetas.

Según el relato de los periodistas, sus sobrinas, la princesa María de las Mercedes y la infanta María Teresa, le dieron «una pulsera de oro con dibujos de turquesas y brillantes» ${ }^{33}$, que quizás sería la de herraduras de turquesas y brillantes apreciada en 1.000 pesetas $^{34}$. Otro «elegantísimo» brazalete de oro, en esta ocasión con forma de serpiente «de gran trabajo y mérito», fue enviado desde Viena por los archiduques Raniero José y María Carolina ${ }^{35}$, pudiéndose tratar del valorado en 1.800 pesetas, con engaste de un brillante.

El broche con nueve hojas de diamantes talla brillante y rosa, valorado en 15.000 pesetas, fue un regalo de sus tíos los duques de Montpensier, y uno de los primeros que recibió. En concreto, se trataba de una rama de hiedra ${ }^{36}$ «del mayor gusto y riqueza» ${ }^{37}$; la cual doña Paz lució a modo de collar en la función de gala celebrada en el Teatro Real el 4 de abril ${ }^{38}$.

Por último, su madre, Isabel II, haciendo gala de su característica generosidad, entregó a doña Paz pieles, encajes, vestidos... y alhajas. Una de ellas fue el

${ }^{27}$ Algunos medios aseguraron que doña Eulalia había entregado una media diadema igual a otra que doña Paz poseía y que ambas habían heredado de su hermana la infanta Pilar, quien prematuramente había fallecido en 1879 [La Época 10.974 (27 de enero de 1883), 3].

${ }^{28}$ La Época 11.039 (4 de abril de 1883), 3.

${ }^{29}$ La Iberia 8.206 (13 de abril de 1883), 2 y La Época 11.049 (14 de abril de 1883), 2.

${ }^{30}$ La Correspondencia de España 9.134 (26 de marzo de 1883), 3.

${ }^{31}$ La Época 11.037 (2 de abril de 1883), 3.

32 La Época 11.030 (26 de marzo de 1883), 3.

${ }^{33}$ Ibíd.

${ }^{34}$ Quizás pudo adquirirse a Francisco Marzo, pues una cuenta de esta joyería fechada en 4 de diciembre de 1883 informa de que doña Mercedes adquirió una muy similar en características y precio: «una pulsera de cadena barbada con herraduras de brillantes y turquesas, 1.125 pesetas» (AGP, Administración General, leg. 328).

${ }^{35}$ La Correspondencia de España 9.134 (26 de marzo de 1883), 3.

${ }^{36}$ A pesar de ser una planta tóxica, la hiedra fue sujeto común de la joyería decimonónica pues, según los repertorios sobre el lenguaje de las flores en boga en la época, era símbolo de fidelidad conyugal [Mrs. L. Burke, The illustrated language of flowers (Londres: G. Routledge \& Co., 1856), 37].

${ }^{37}$ El Día 985 (9 de febrero de 1883), 2 y La Época 11.017 (12 de marzo de 1883), 3.

${ }^{38}$ La Época 11.040 (5 de abril de 1883), 2. 
devocionario tasado en 12.500 pesetas, el cual había pertenecido a María Cristina de Borbón-Dos Sicilias, abuela materna de la novia. Calificado de «maravilla de arte y riqueza» por quien tuvo la oportunidad de admirarlo de cerca, tenía las cubiertas de oro sembradas de numerosos brillantes de diversos tamaños, y contaba con adornos del mismo metal cincelados y de hojarasca esmaltada de verde en relieve sobre un fondo de esmalte rosa. Las tapas estaban ornamentadas, además, con dos «deliciosas» miniaturas, una representando al Niño Jesús con la cruz y la otra reproduciendo el cuadro de la Sagrada Familia, llamada La Perla, de Rafael ${ }^{39}$. Sorprendentemente, una de ellas se abría por medio de un resorte oculto en la pedrería para dejar a la vista un reloj de diminuto tamaño. En el canto llevaba las armas de España y por cierre una cruz de brillantes $^{40}$. La infanta portó este tesoro entre las manos el día de su boda ${ }^{41}$.

Doña Isabel obsequió, igualmente, el aderezo de diamantes y rubíes apreciado en 135.000 pesetas. No se trataba, tampoco, de alhajas adquiridas para la ocasión, sino el resultado de la modificación parcial de un conjunto de su propiedad ${ }^{42}$. Había estado compuesto por un collar con «orlas de brillantes, otra de rosas y el rubí y entre las orlas un brillante, todas las orlas las ata una solista de brillantes, además cuelgan del centro tres almendras centro de rubí y orla de brillantes»; un broche para el pecho con «cinco orlas de brillantes con un rubí en el centro y sobrepuestas a estas hay cuatro pequeñas orlas con un rubí, de las cinco orlas cuelgan dos cartones festoneados y un hilo de engastes y de éstos cuatro almendras de rubí con orlas de brillantes»; una pulsera con «orlas de brillantes, un rubí en el centro, unas barras festoneadas por entrepiezas» y un par de pendientes con «orla de brillantes y rubí en el centro, engaste de un brillante intermedio y orla con una almendra de rubí en el centro» ${ }^{43}$ (fig. 2 ).

\footnotetext{
39 Pintada hacia 1518, representa a la Virgen María, al Niño, a san Juanito y a santa Ana. Ingresó en las colecciones reales en tiempo de Felipe IV y en 1857 en el Museo del Prado, donde todavía hoy se conserva [Museo Nacional del Prado, "Sagrada Familia, llamada La Perla", P-301: https://www.muse odelprado.es/coleccion/obra-de-arte/sagrada-familia-llamada-la-perla/f3d745b8-f800-437a-a6649f3d065ce127 (última consulta: 30 de agosto de 2020)]. Durante el siglo XIX fue habitual la reproducción en miniatura de pinturas marianas de grandes maestros renacentistas, especialmente de Rafael.

${ }^{40}$ AHN, Diversos, Colecciones, Diplomática, leg. 292, exp. 5; La Época 11.026 (21 de marzo de 1883), 3; La Época 11.030 (26 de marzo de 1883), 3 y La Correspondencia de España 9.134 (26 de marzo de 1883), 3.

${ }^{41}$ La Época 11.037 (2 de abril de 1883), 3.

${ }^{42}$ La Época 11.026 (21 de marzo de 1883), 3.

43 AHN, Diversos, Colecciones, Diplomática, leg. 292, exp. 5.
} 


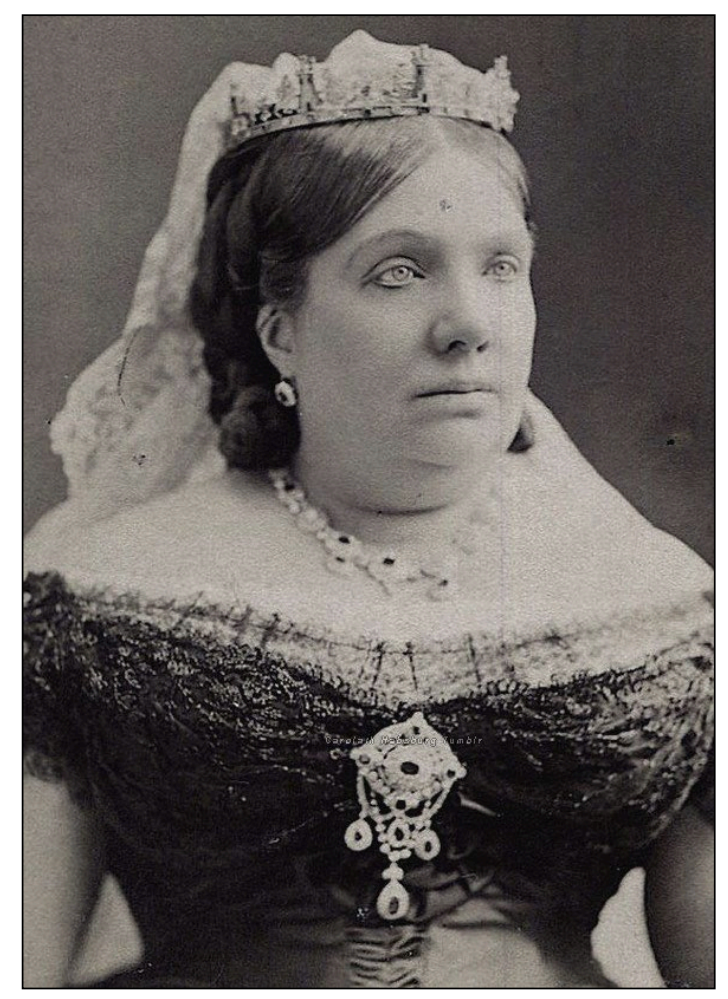

Fig. 2- Alphonse Liébert, La reina Isabel II, década de 1870. Ubicación actual desconocida. La fotografía muestra el broche, el collar y el cuerpo superior de los pendientes (desmontables, como era habitual) del aderezo de diamantes y rubíes. La corona de torres, leones y lises sería heredada por doña Paz a la muerte de su madre.

Los detalles del nuevo aderezo se conocen por medio de un documento muy posterior al enlace de doña Paz, firmado el 9 de mayo de 1906 por Peter Rath, joyero muniqués que tasó el conjunto en 45.000 marcos (equivalentes a 55.350 pesetas) y describió que estaba integrado por un collar con diecisiete rubíes, doscientos setenta y un brillantes y diversas rosas (21.000 marcos); un gran broche de festones con nueve rubíes y diversos brillantes (10.000); un broche pequeño con dos rubíes y veintiséis brillantes (900 marcos); un brazalete con dos rubíes y brillantes (3.300 marcos); un par de pendientes con dos rubíes y veintidós brillantes (2.300 marcos) y nueve estrellas con nueve rubíes y diversos brillantes $(7.500 \text { marcos })^{44}$.

En cuanto a las estrellas ${ }^{45}$, procedían, a su vez, de una diadema realizada por el joyero parisino Dumoret, la cual, según factura de 30 de noviembre de 1861, costó 120.000 reales $^{46}$, habiendo estado formada, en origen, por once estrellas de diamantes

44 AGP, Histórica, c. 159, exp. 1.

${ }^{45}$ Para profundizar en la historia del empleo de cuerpos celestes como motivos de la joyería, véase: Fritz Falk, Himmlisch. Sonne, Mond und Sterne im Schmuck. / Heavenly. The Sun, Moon and stars in jewellery (Stuttgart: Arnoldsche Art Publishers, 2016).

46 AGP, Administración General, leg. 5.263, exp. 8. La factura ya fue publicada por Aranda Huete, "Panorama", 15. 
montados en oro con vistas en plata, con un rubí talla oval en cada centro ${ }^{47}$. La versatilidad de la joya permitía que los astros pudieran lucirse de esta manera o desligarse de la estructura y usarse como broches. Por ejemplo, Isabel II prendió cuatro de las estrellas en la cintura del traje de reina Ester con el que acudió a la fiesta de disfraces organizada por los duques de Fernán Núñez en abril de 1863 (fig. 3), y la infanta Paz asistió a su baile nupcial, ofrecido el 5 de abril en el Palacio Real, con algunas de ellas asidas a una cinta que ajustó al contorno del cuello, detalle del que informaron los cronistas de sociedad que cubrieron el evento y como puede deducirse del dibujo tomado del natural por Juan Comba para La Ilustración Española y Americana ${ }^{48}$. El 15 de mayo de 2003, los descendientes de doña Paz subastaron en la sede ginebrina de Christie's ocho de las estrellas (dos de ellas transformadas en pendientes) ${ }^{49}$, ascendiendo el remate a 59.750 francos suizos ${ }^{50}$ (fig. 4).

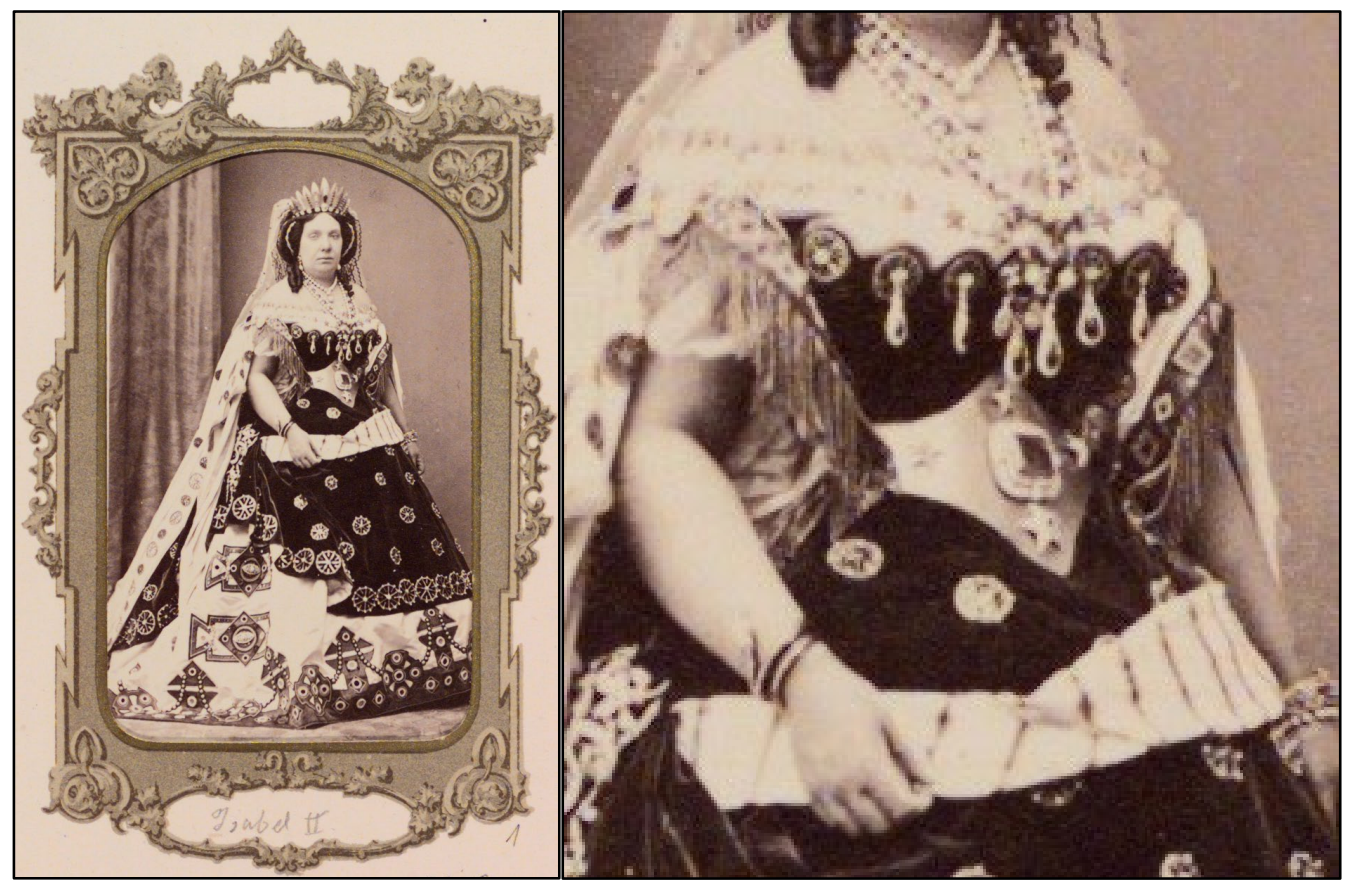

Fig. 3- Pedro Martínez de Hebert, Isabel II ataviada como la reina Ester, 1863. CPatrimonio Nacional, Real Biblioteca (inv. 10185258).

47 AHN, Diversos, Colecciones, Diplomática, leg. 292, exp. 5.

${ }^{48}$ La Época 11.041 (6 de abril de 1883), 2 y La Ilustración Española y Americana 14 (15 de abril de 1883), 236.

${ }^{49} \mathrm{El}$ ancho de las estrellas oscila entre 2,6 y 3,6 cm.

${ }^{50}$ Christie's, "A set of eight antique diamond and ruby stars", http://www.christies.com/lotfinder/ lot/a-set-of-eight-antique-diamond-and-4102113-details.aspx (última consulta: 30 de abril de 2020). 


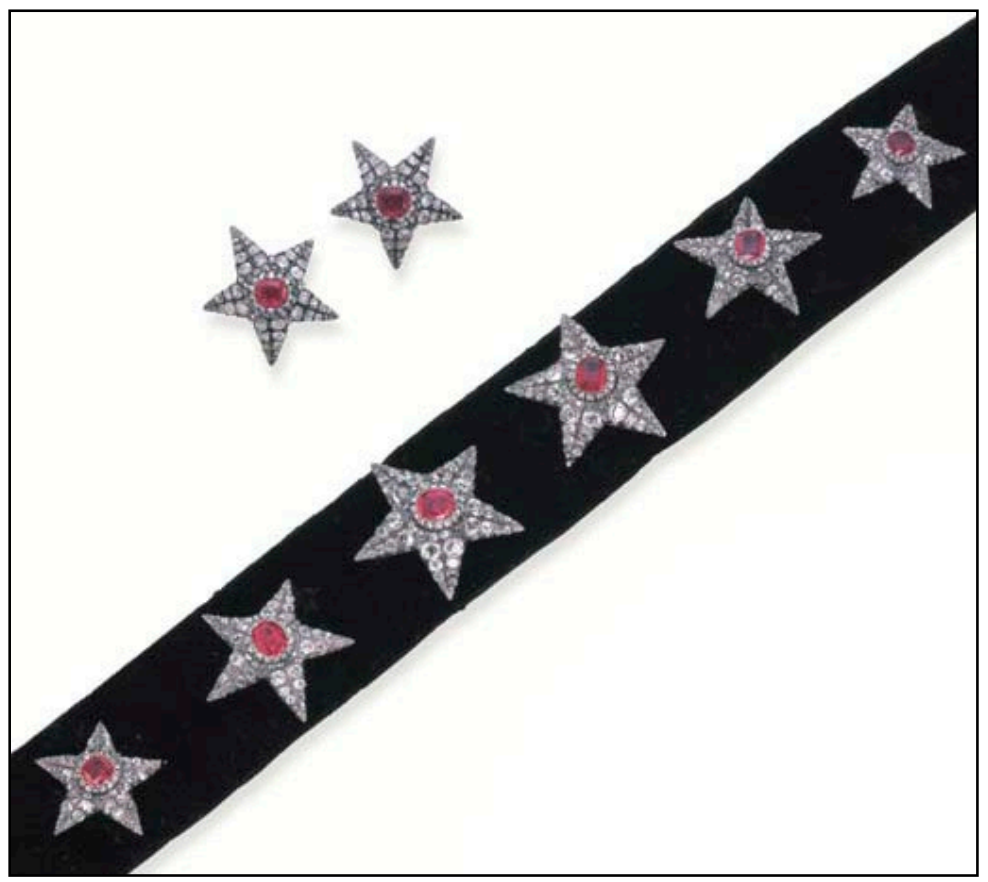

Fig. 4- Dumoret, Estrellas de diamantes con rubi en los centros, 1861. Colección privada (fotografía: (C)Christie's).

Aunque sea brevemente, resulta interesante relatar que, ya en el exilio, Isabel II entregó devocionario, aderezo y diadema (junto a la práctica totalidad de su joyero) al Banco de Inglaterra el 1 de julio de 1872, como garantía del préstamo de 40.000 libras esterlinas concedido por la financiera londinense Zulueta y Cía ${ }^{51}$. Su secretario particular, el político y dramaturgo Tomás Rodríguez y Díaz Rubí, redactó un inventario como parte del protocolo de depósito, para el que tuvo como referencia una relación hecha en España en 1868. Además de las descripciones expuestas líneas atrás, el texto permite conocer que el devocionario se tasó en 40.000 reales en 1868 y en 9.500 en 1872 , el aderezo en 440.000 reales en 1868 y en 185.000 en 1872 y la diadema en 200.000 reales en 1868 y en 50.000 en 1872. El inventario del señor Rodríguez fue ampliado, corregido y ratificado por doña Isabel en París el 30 de noviembre de $1874^{52}$. En 1875, todas las joyas regresaron a manos de su propietaria, quedando en el Palacio de Castilla de París bajo la custodia del diamantista Manuel Congosto ${ }^{53}$. Con probabilidad, los futuros regalos para la infanta Paz fueron integrantes del conjunto de alhajas que, el 8 de abril de 1876, se consignó en el Banco de Francia para garantizar las pensiones que, la ya reina madre, estaba obligada a abonar a su esposo e hijos ${ }^{54}$. Finalmente, los problemas económicos de doña Isabel desembocaron en la venta que de un gran número de sus joyas albergó el Hôtel Drouot de París en el verano de 1878.

\footnotetext{
${ }^{51}$ Biblioteca de la Real Academia de la Historia, 9/6963, leg. XXIV, núm. 27.

52 AHN, Diversos, Colecciones, Diplomática, leg. 292, exp. 5.

53 AGP, Administración General, leg. 1160, exp. 1.

${ }^{54}$ AGP, Reinados, Alfonso XII, c. 25019, exp. 12.
} 
En el catálogo editado para la ocasión solamente el devocionario aparece referido, siendo calificado de «travail ramarquable» ${ }^{55}$. Evidentemente, no se adjudicó, bien porque fue retirado a tiempo de la subasta, bien porque no encontró comprador.

Retrocediendo en el discurso, otras joyas, en cambio, no aparecen recogidas en el inventario nupcial porque fueron regaladas posteriormente a su redacción. Tal fue el caso del «lindo aderezo de coral rosa de Nápoles ${ }^{56}$, de gran mérito, por estar todo formado de gruesas bolas, collar, dos brazaletes, peineta, pendientes y broche» obsequiado por la condesa de Llorente; la «rica sortija con una gran turquesa, rodeada de brillantes» ofrecida por la condesa de Sorróndegui ${ }^{57}$; el alfiler de brillantes con forma de murciélago dado por su tía la infanta María Cristina de Borbón ${ }^{58}$; o la «preciosa flor de lis de brillantes» que su padre, Francisco de Asís de Borbón, le entregó personalmente en París y que la desposada prendió en el corpiño del traje que lució en el ya citado baile organizado por la Embajada de España en la capital francesa ${ }^{59}$. Además, con toda seguridad, fue el rey Luis II de Baviera quien agasajó a doña Paz con el brazalete de oro, diamantes talla rosa, cabujón de zafiro sintético y gemas rojas, representando una estrella enmarcada por un par de cisnes ${ }^{60}$ afrontados y envueltos en vegetación, que fue subastado por los descendientes de la princesa el 15 de mayo de 2012 en la sede de Sotheby's en Ginebra, vendiéndose por 23.750 francos suizos ${ }^{61}$ (fig. $5)$.

55 Dubourg, Guidou, Dumoret y Lamarche-Vinit, Catalogue des diamants anciens, émeraudes, saphirs, rubis, perles, camées appartenant à $S$. M. la reine Isabelle de Bourbon (París: Renou, Maulde et Cock, imprimeurs de la compagnie des commissaires-priseurs, 1878), 5.

56 Se especifica la procedencia porque el centro manufacturero más prestigioso se hallaba allí, concretamente en la localidad de Torre del Greco. Ligado a la joyería popular de ciertas áreas del Mediterráneo y a la protección mágica de la infancia desde tiempos inmemoriales, el coral se convirtió en el siglo XIX en un material de moda. Cuando era de color rosa muy pálido recibía el nombre de piel de ángel.

${ }^{57}$ La Correspondencia de España 9.134 (26 de marzo de 1883), 3 y La Época 11.030 (26 de marzo de 1883), 2.

${ }^{58}$ La Época 11.030 (26 de marzo de 1883), 3.

${ }^{59}$ La Época 11.049 (14 de abril de 1883), 2 y La Moda Elegante 16 (30 de abril de 1883), 5.

${ }^{60} \mathrm{La}$ adopción del cisne como animal emblemático por parte de Luis II de Baviera se gestó desde la infancia. En 1832, su padre, futuro Maximiliano II, adquirió las ruinas de la fortaleza de Schwanstein (cisne de piedra), sobre la que edificó el castillo neogótico de Hohenschwangau (alto condado del cisne), que se convirtió en la residencia estival de la familia. Considerándose sucesor de los señores de Schwangau, primeros propietarios del lugar, Maximiliano tomó por propio su blasón con figura de cisne. Este ave estaba tradicionalmente ligada a un cuento medieval sobre un caballero sin nombre que llegaba al auxilio de una doncella en apuros a bordo de una barca conducida por un cisne, argumento que Richard Wagner trasladó a su ópera Lohengrin, estrenada en 1850. La fascinación por el universo wagneriano y el peso del pasado local motivaron que Maximiliano ornamentara su castillo con cisnes heráldicos y escenas legendarias que espolearon la imaginación de su heredero, quien se haría rodear de esta iconografía, materializada en su máxima expresión en el castillo rebautizado tras su muerte y actualmente conocido como Neuschwanstein (nuevo cisne de piedra).

${ }^{61}$ Sotheby's, "Gold and diamond bangle, circa 1850", http://www.sothebys.com/en/auctions/eca talogue/2012/magnificent-jewels-and-noble-jewels/lot.548.html (última consulta: 7 de diciembre de 2020). 


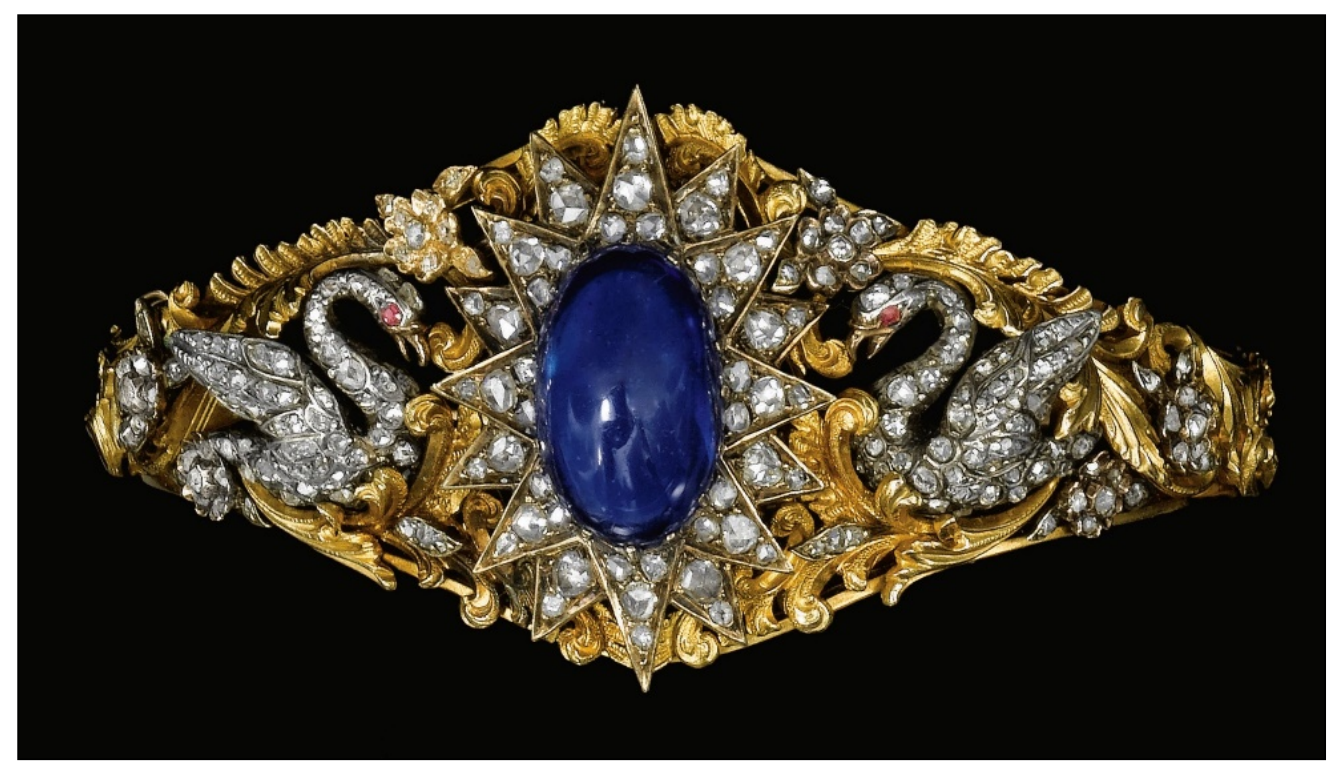

Fig. 5- Anónimo muniqués, Brazalete de oro, diamantes, zafiro sintético y gemas rojas figurando una estrella, dos cisnes y motivos vegetales, h. 1883. Colección privada (fotografía: CSotheby’s).

\section{JOYAS RETRATADAS}

Durante su adolescencia y primera juventud, el alhajamiento de la infanta Paz fue extremadamente sencillo. En sus retratos se repiten los tornillos de perla (de los que poseía dos pares, tasados en 800 y 900 pesetas) y las pulseras rígidas llevadas en ambos antebrazos, como la que destaca en primer término en la imagen tomada por Fernando Debas hacia 1880: una pieza ancha, plana y con ornamento en forma de gota con una perla o diamante en el interior; joya que, evidentemente, existió, pero que no ha podido ser identificada en el inventario, escueto en muchas de sus descripciones (fig. 6).

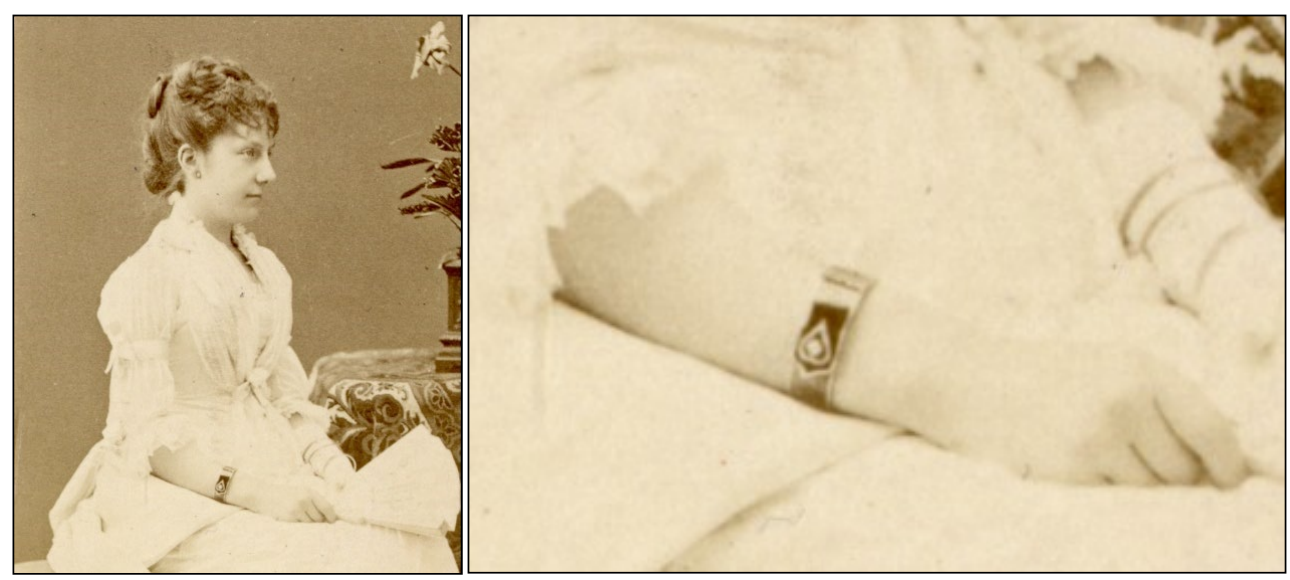

Fig. 6- Fernando Debas, La infanta Paz de Borbón (detalle), h. 1880. CPatrimonio Nacional, Archivo General de Palacio (inv. 10180199). 
Misma incógnita concurre en el caso de los dos siguientes broches: el primero, con diseño de letra $\mathrm{M}$, se muestra en una imagen captada en los años previos a su matrimonio (fig. 7), y el segundo, figurando un banderín que aparenta ser de oro con el fondo esmaltado, en otra realizada inmediatamente después de su enlace (fig. 8).

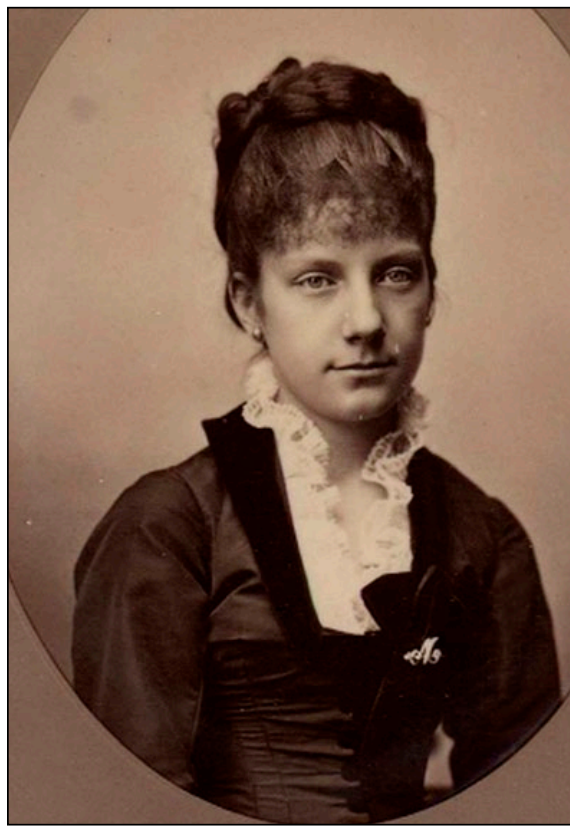

Fig. 7- Fotógrafo desconocido, La infanta Paz. de Borbón, h. 1880. Ubicación actual desconocida.

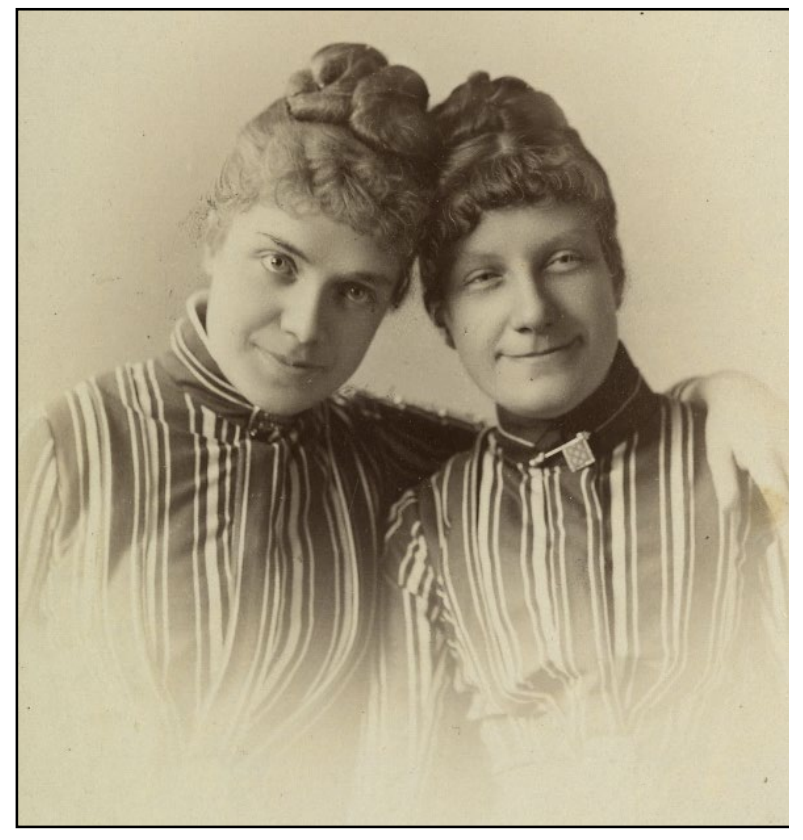

Fig. 8- Joseph Albert, Las infantas Eulalia y Paz de Borbón, h. 1883. CPatrimonio Nacional, Real Biblioteca (inv. 10214354).

Hacia 1875 Luis Franco pintó, pendiendo de una cinta de color negro, un medallón ovalado de oro (que probablemente haría la función de guardapelo) con la inicial de la infanta coronada (fig. 9). Tampoco esta joya se halla entre los bienes de doña Paz, pero puede asegurarse que no fue una licencia del artista porque se distingue en una foto (que no ha podido ser reproducida) en la que, además, la joven aparece vestida y peinada como en el óleo, en compañía esta vez de sus hermanas Pilar y Eulalia, igualmente ataviadas. 


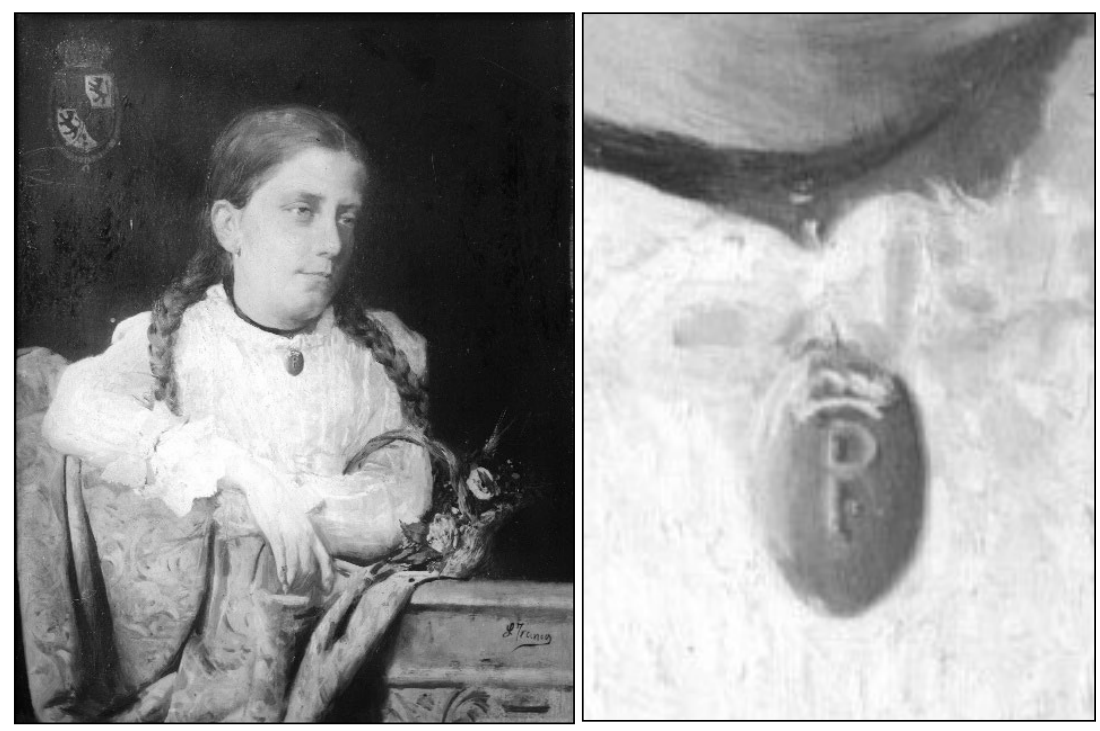

Fig. 9- Luis Franco, La infanta Paz de Borbón, h. 1875. CPatrimonio Nacional, Palacio Real de Aranjuez (inv. 10023555).

Por el contrario, en un dibujo trazado con tinta y grafito sobre opalina poco antes de la formalización de su compromiso, cierra el cuello de la chaqueta el original broche con forma de paleta de pintor que tenía engastados una turquesa, un ópalo, rubíes y diamantes talla rosa para simular las manchas de color, alhaja que en 1883 fue valorada en 300 pesetas (fig. 10).

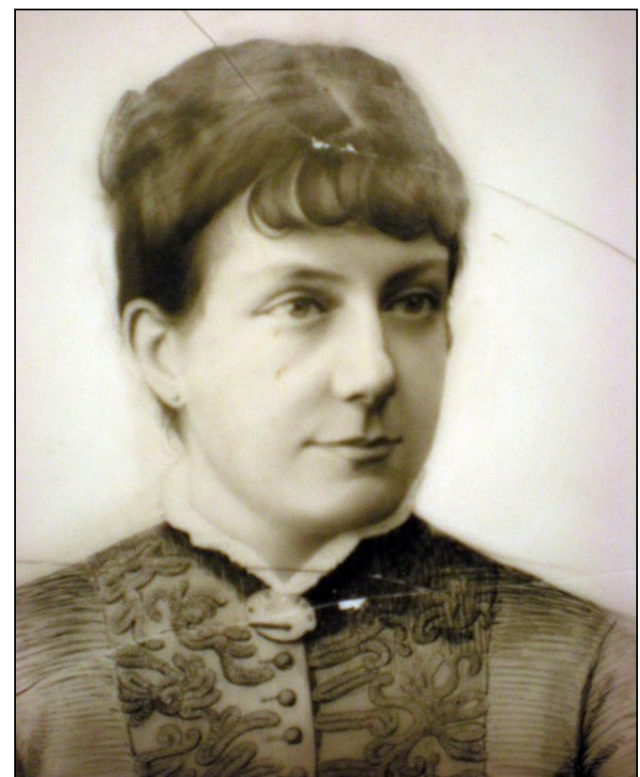

Fig. 10- Anónimo, La infanta Paz de Borbón, 1882. CPatrimonio Nacional, Palacio Real de Madrid (inv. 10222353). 
Después de instalarse en su nuevo hogar, doña Paz fue fotografiada por el muniqués Joseph Albert. Destacan sobre el hombro y pecho izquierdos las dos flores de lis de brillantes valoradas en 5.800 pesetas y en el centro del escote la regalada por don Francisco de Asís (fig. 11).

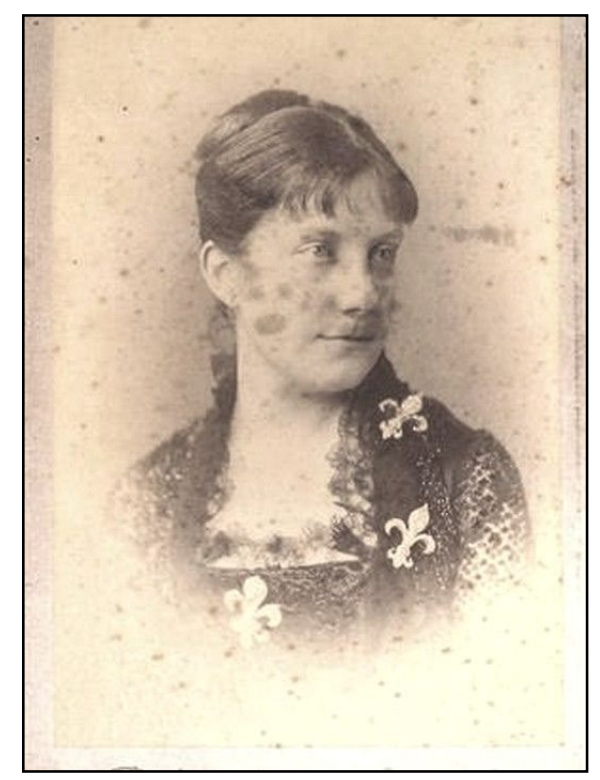

Fig. 11- Joseph Albert, Paz de Borbón, infanta de España y princesa de Baviera, h. 1883. Ubicación actual desconocida.

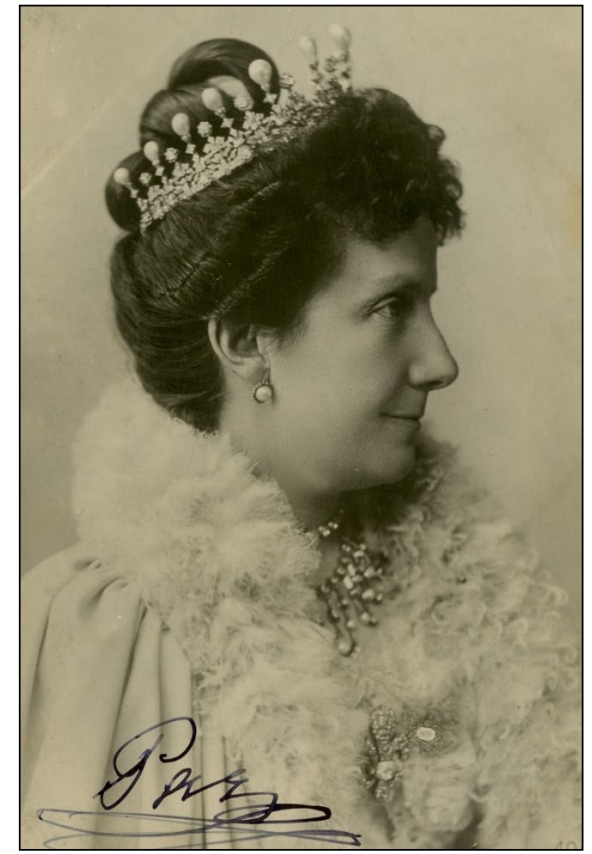

Fig. 12- Manuel Palomeque, Paz. de Borbón, infanta de España y princesa de Baviera, década de 1890. (C) Patrimonio Nacional, Archivo General de Palacio (inv. 10239011). 
Esta última puede verse en detalle en una imagen captada en la década de 1890, que permite apreciar cómo la superficie de la joya estaba cuajada de diamantes, destacando uno de gran quilataje en la base del motivo heráldico. Otro presente nupcial engalana la testa de la princesa de Baviera, esto es, la ya mencionada diadema ofrecida por la infanta Eulalia, que estaba compuesta por una crestería de trece perlas perilla (dispuestas en tamaño decreciente hacia los extremos) en alternancia con doce brillantes, sobre una base calada donde se asentaban los más de mil diamantes citados, creando geometrías de inspiración vegetal. Alrededor del cuello se reconocen, primero, la rivière de treinta y ocho chatones de brillantes tasada en 6.000 pesetas, y, por debajo, el collar valorado en 36.500 pesetas, formado por un hilo de gruesos brillantes complementados por rosas y colgantes con perlas. Los pendientes, con una perla orlada de pequeños diamantes, concluyen el alhajamiento (fig. 12).

Retrocediendo en el tiempo, doña Paz, asentada temporalmente en Madrid para dar a luz a su primer hijo, fue invitada al baile de trajes celebrado por los duques de Fernán Núñez el 25 de febrero de 1884, adonde acudió disfrazada de dama rococó. En la fotografía, tomada por Fernando Debas e iluminada por Enrique Rumoroso, se observa que el tocado de plumas queda asido por la flor de brillantes que le fue obsequiada por la reina María Cristina (fig. 13). La princesa debió de usarla habitualmente como prendedor para la cabeza, pues en la fotografía realizada en enero de 1906 con motivo del enlace de la infanta María Teresa de Borbón y Austria (su sobrina) con el príncipe Fernando María de Baviera y Borbón (su primogénito), doña Paz la luce sujetando el velo de encaje negro (fig. 14).

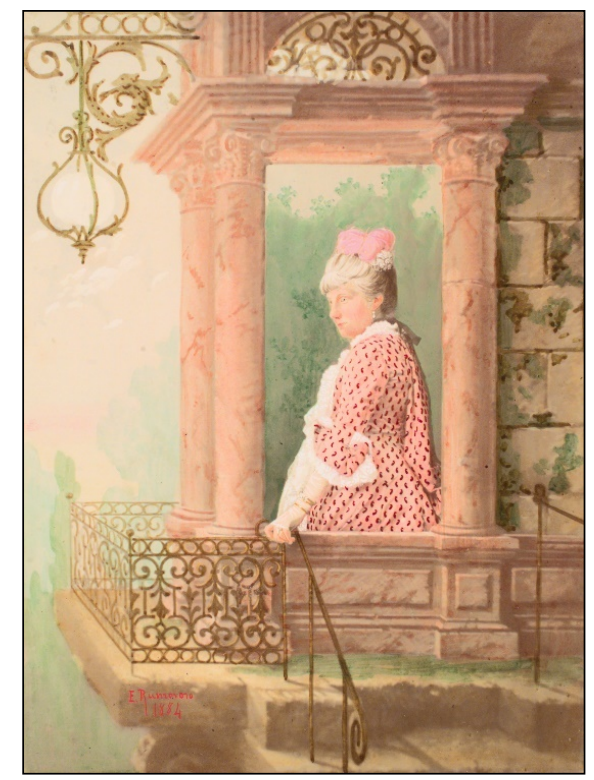

Fig. 13- Fernando Debas (fotógrafo) y Enrique Rumoroso (pintor), La infanta Paz de Borbón vestida de dama de la época de Watteau, 1884. (C) Patrimonio Nacional, Real Biblioteca (inv. 10162525).

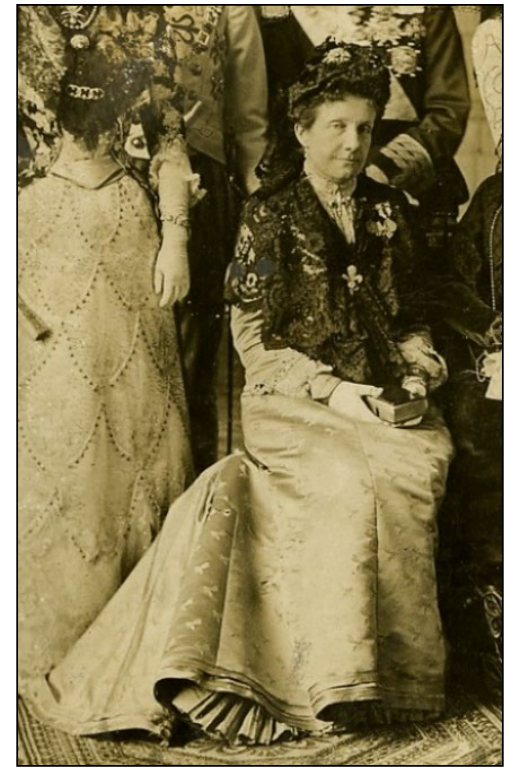

Fig. 14- Fotógrafo desconocido, Reunión familiar en el Palacio Real de Madrid en vísperas de la boda de la infanta María Teresa (detalle de la infanta Paz de Borbón), 1906. CPatrimonio Nacional, Archivo General de Palacio (inv. 10214579). 
Otro regalo nupcial se muestra en una fotografía datada en los primeros años del siglo XX; esto es, el hilo de magníficas perlas regalado por la infanta Isabel, colocado en dos vueltas: una ciñendo el cuello y la otra cayendo más allá del busto. De buen calibre son también las perlas de los pendientes. Igualmente, adornando el peinado se descubren tres de las ocho estrellas de brillantes con centros de perla apreciadas en 10.000 pesetas en 1883 (fig. 15).

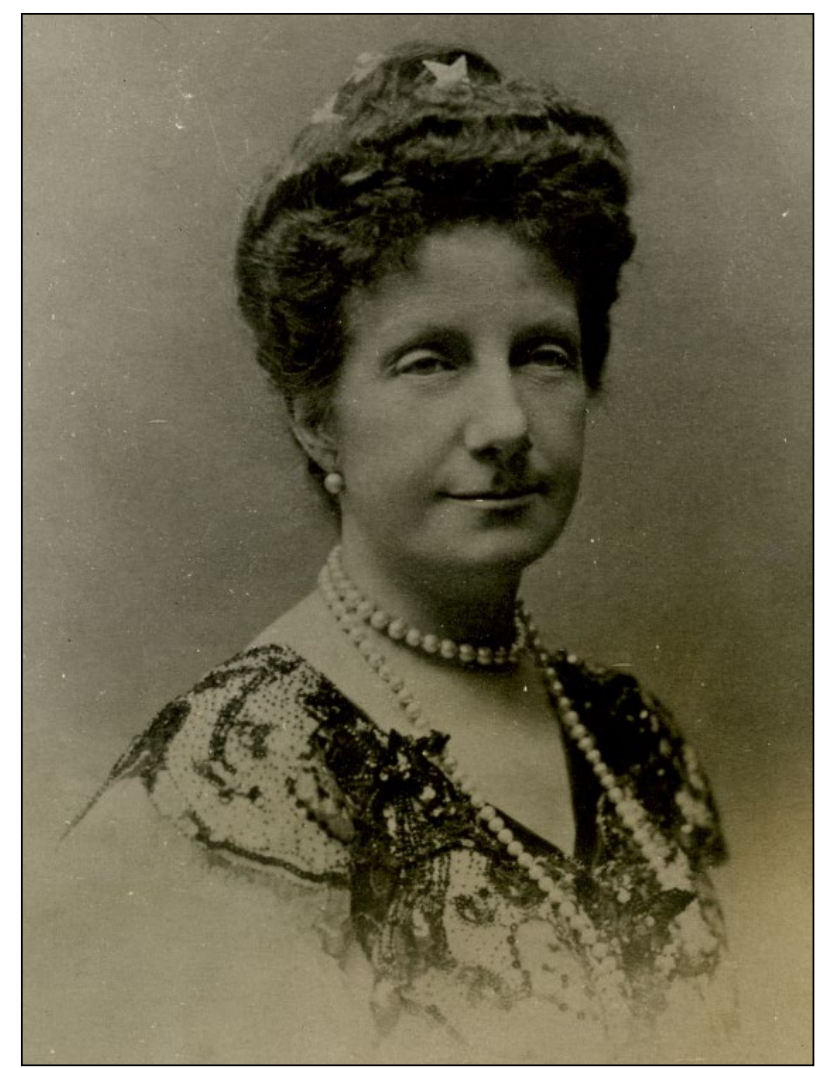

Fig. 15- Christian Franzen y Nissen, Paz de Borbón, infanta de España y princesa de Baviera, 1906. (C) Patrimonio Nacional, Archivo General de Palacio (inv. 10213912). 


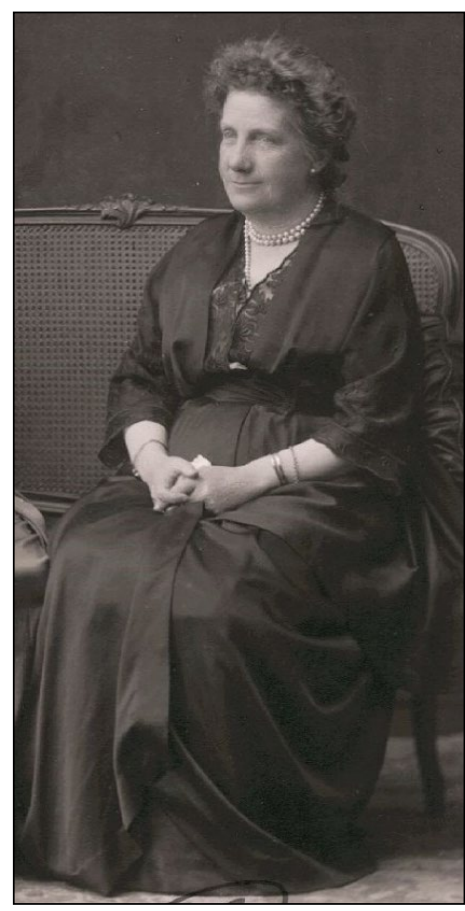

Fig. 16- Christian Franzen y Nissen, La reina Maria Cristina de Habsburgo y las infantas Isabel, Pazy Eulalia de Borbón (detalle de la infanta Paz), década de 1920. CPatrimonio Nacional,

Archivo General de Palacio (inv. 10141754).

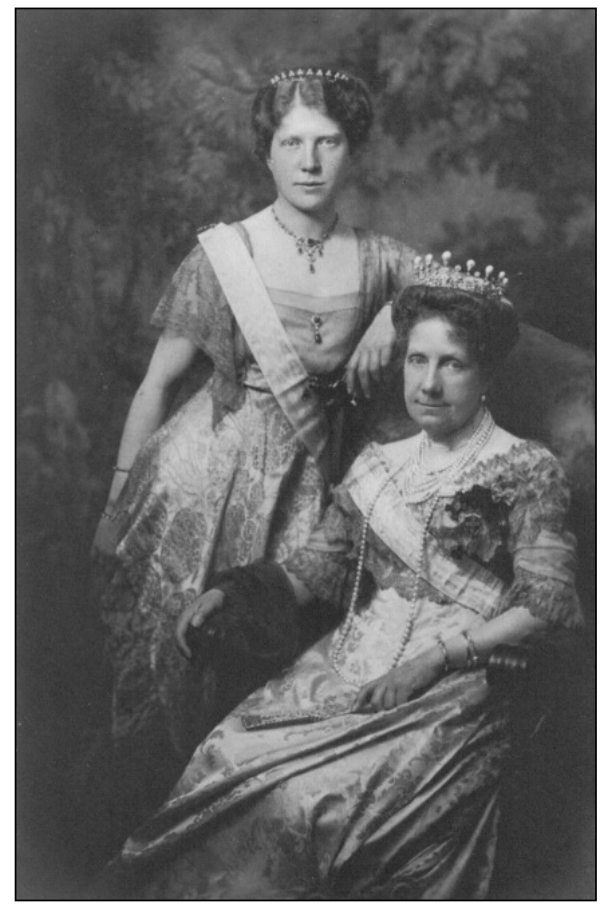

Fig. 17- Fotógrafo desconocido, La infanta Paz de Borbón y su hija la princesa Pilar de Baviera, década de 1910. Ubicación actual desconocida.

Para una fotografía posterior, fechable en la década de 1920, doña Paz posó con el mismo collar, en esta ocasión dispuesto en tres vueltas (fig. 16). Por último, la fotografía hecha hacia 1910, en la que aparece acompañada de su hija la princesa Pilar, permite constatar el largo total del collar. Además, entre éste y la gargantilla de tipo ahogador o collier de chien, tan en boga en la época, se hallan seis hilos de perlas más menudas que podrían identificarse con el collar tasado en 30.400 pesetas en el inventario al que se han dedicado estas páginas, cuyo cierre consistía en un camafeo guarnecido de brillantes (fig. 17). 


\section{REFERENCIAS BIBLIOGRÁFICAS}

\section{Documentación de archivo}

Archivo General de Palacio, Administración General, leg. 328.

Archivo General de Palacio, Administración General, leg. 907.

Archivo General de Palacio, Administración General, leg. 1.160, exp. 1 y 3.

Archivo General de Palacio, Administración General, leg. 5.263, exp. 8.

Archivo General de Palacio, Administración General, c. 152.

Archivo General de Palacio, Histórica, c. 159, exp. 1.

Archivo General de Palacio, Reinados, Alfonso XII, c. 25.019, exp. 12.

Archivo Histórico Nacional, Diversos, Colecciones, Diplomática, leg. 292, exp. 5.

Biblioteca de la Real Academia de la Historia, 9/6963, leg. XXIV, núm. 27.

\section{Hemerografia}

El Día 985 (9 de febrero de 1883), 2.

La Correspondencia de España 9.134 (26 de marzo de 1883), 3.

La Época 10.972 (25 de enero de 1883), 3.

La Época 10.974 (27 de enero de 1883), 3.

La Época 11.003 (26 de febrero de 1883), 3.

La Época 11.017 (12 de marzo de 1883), 3.

La Época 11.026 (21 de marzo de 1883), 3.

La Época 11.030 (26 de marzo de 1883), 2 y 3.

La Época 11.037 (2 de abril de 1883), 3.

La Época 11.039 (4 de abril de 1883), 3. 
La Época 11.040 (5 de abril de 1883), 2.

La Época 11.041 (6 de abril de 1883), 2.

La Época 11.049 (14 de abril de 1883), 2.

La Iberia 8.206 (13 de abril de 1883), 2.

La Ilustración Española y Americana 14 (15 de abril de 1883), 236.

La Moda Elegante 16 (30 de abril de 1883), 5.

Bibliografía

Álvarez, María Teresa, La infanta Paz, de Borbón (Madrid: La Esfera de los Libros, 2011).

Aranda Huete, Amelia, "La casa Celestino de Ansorena e Hijos, joyeros de la Corona española”, Anales del Instituto de Estudios Madrileños 59 (2019), 57-122.

—, "Panorama de la joyería española durante el reinado de Isabel II", Boletín del Museo e Instituto Camón Aznar 68 (1997), 5-24.

Bennett, David y Daniela Mascetti, Understanding jewellery (Londres: Antique Collectors' Club, 2008).

Borbón, Paz de, Cuatro revoluciones e intermedios: setenta años de mi vida (Madrid: EspasaCalpe, 1935).

_,De mi vida: impresiones (Madrid: Imprenta del Asilo de la Santísima Trinidad, 1909).

Burke, Mrs. L., The illustrated language of flowers (Londres: G. Routledge \& Co., 1856).

Bury, Shirley, Jewellery. The international era, 1789-1910. Vol. II: 1862-1910 (Woodbridge: Antique Collectors' Club, 1997).

Dubourg, Guidou, Dumoret y Lamarche-Vinit, Catalogue des diamants anciens, émeraudes, saphirs, rubis, perles, camées appartenant à S. M. la reine Isabelle de Bourbon (París: Renou, Maulde et Cock, imprimeurs de la compagnie des commissairespriseurs, 1878).

Falk, Fritz, Himmlisch. Sonne, Mond und Sterne im Schmuck / Heavenly. The Sun, Moon and stars in jewellery (Stuttgart: Arnoldsche Art Publishers, 2016). 
Koch, Michael (ed.), The Belle Époque of French jewellery, 1850-1910 (Londres: Thomas Heneage, 1991).

Lázaro Milla, Nuria, "El inventario de joyas de la infanta Isabel de Borbón y Borbón realizado con motivo de sus nupcias", Librosdelacorte.es 20 (2020), 100-128.

—, "El reparto de joyas tras la muerte de Isabel II, un proceso problemático", en coord. Alejandro Cañestro Donoso, Scripta artivm in honorem prof. José Manuel Cruz Valdovinos (Alicante: Universidad de Alicante, 2018), 268-295.

-, "Joyas compradas con cargo al bolsillo secreto de las infantas Isabel, Pilar, Paz y Eulalia y el príncipe Alfonso de Borbón, 1863-1868”, en coord. Jesús Rivas Carmona e Ignacio José García Zapata, Estudios de Platería. San Eloy 2020 (Murcia: Universidad de Murcia, 2020), 137-149.

Martín, Fernando A., “Ansorena, joyeros y diamantistas reales”, en VV. AA., Ansorena, 150 años en la joyería madrileña (Madrid: Ansorena, 1995), 29-51.

Vever, Henri, La bijouterie française au XIX ${ }^{e}$ siècle, 1800-1900. Vol. II: Second Empire, 18501870 (París: H. Floury, 1908).

Vever, Henri, La bijouterie française au XIX'e siècle, 1800-1900. Vol. III: Troisième République, 1870-1900 (París: H. Floury, 1908).

VV. AA., Joyas del siglo XIX (Barcelona: Planeta-De Agostini, 1989).

\section{Recursos online}

Christie's, "A set of eight antique diamond and ruby stars",

http://www.christies.com/lotfinder/lot/a-set-of-eight-antique-diamond-and4102113-details.aspx (última consulta: 30 de abril de 2020).

Museo Nacional del Prado, "Sagrada Familia, llamada La Perla", https://www.museodelprado.es/coleccion/obra-de-arte/sagrada-familia-llamada-laperla/f3d745b8-f800-437a-a664-9f3d065ce127 (última consulta: 30 de agosto de 2020).

Sotheby's, "Diamond tiara, circa 1900",

http://www.sothebys.com/es/auctions/ecatalogue/2013/magnificent-jewels-andnoble-jewels-ge1302/lot.368.html (última consulta: 6 de mayo de 2020).

Sotheby's, "Gold and diamond bangle, circa 1850", http://www.sothebys.com/en/auctions/ecatalogue/2012/magnificent-jewels-andnoble-jewels/lot.548.html (última consulta: 7 de diciembre de 2020). 
Recibido: 31 de agosto de 2020 Aprobado: 24 de noviembre de 2020 